\title{
Emerging roles for telemedicine and smart technologies in dementia care
}

This article was published in the following Dove Press journal:

Smart Homecare Technology and TeleHealth

23 March 2015

Number of times this article has been viewed

\author{
Ann L Bossen' \\ Heejung Kim ${ }^{2,3}$ \\ Kristine N Williams' \\ Andreanna E Steinhoff ${ }^{2}$ \\ Molly Strieker ${ }^{\prime}$ \\ 'University of lowa College \\ of Nursing, lowa City, IA, USA; \\ ${ }^{2}$ University of Kansas School \\ of Nursing, Kansas City, KS, USA; \\ ${ }^{3}$ Yonsei University College of Nursing, \\ Seoul, Republic of Korea
}

\begin{abstract}
Demographic aging of the world population contributes to an increase in the number of persons diagnosed with dementia (PWD), with corresponding increases in health care expenditures. In addition, fewer family members are available to care for these individuals. Most care for PWD occurs in the home, and family members caring for PWD frequently suffer negative outcomes related to the stress and burden of observing their loved one's progressive memory and functional decline. Decreases in cognition and self-care also necessitate that the caregiver takes on new roles and responsibilities in care provision. Smart technologies are being developed to support family caregivers of PWD in a variety of ways, including provision of information and support resources online, wayfinding technology to support independent mobility of the PWD, monitoring systems to alert caregivers to changes in the PWD and their environment, navigation devices to track PWD experiencing wandering, and telemedicine and e-health services linking caregivers and PWD with health care providers. This paper will review current uses of these advancing technologies to support care of PWD. Challenges unique to widespread acceptance of technology will be addressed and future directions explored.
\end{abstract}

Keywords: technology, dementia care, caregiver support

\section{Demographic trends associated with older adults experiencing cognitive decline}

As life expectancies increase, Americans are living longer with more chronic conditions than ever before. The number of adults aged 65 years and older is expected to double from 40.2 million in 2010 to 88.5 million in $2050 .{ }^{1}$ According to the United States Department of Health and Human Services, ${ }^{2}$ older adults are living with chronic conditions such as arthritis $(50 \%)$, heart disease (30\%), cancer (24\%), diabetes $(20 \%)$, and hypertension (72\%). Cognitive impairments are also prevalent in this aging population, ranging from age-specific memory loss to clinically diagnosed dementia. Population-based studies have found that $28 \%$ of community-dwelling older adults have mild cognitive changes such as memory loss; this includes $19 \%$ of adults aged over 65 years and $29 \%$ of those aged over 85 years. ${ }^{3}$ Currently, $11 \%$ of older adults are living with Alzheimer's disease (AD) and other types of dementia.

Older adults with cognitive impairments, even mild, are at a higher risk of developing $\mathrm{AD}$, with an annual conversion rate from mild cognitive impairment to $\mathrm{AD}$ of $3 \%-13 \%$, which is significantly higher than the rate in those without cognitive impairment ( $1 \%$ per year). ${ }^{4} \mathrm{~A}$ new case of $\mathrm{AD}$ is diagnosed every minute, and the annual incidence of $\mathrm{AD}$ and other dementias is projected to double by $2050 .{ }^{5}$ Thus, the number of persons 
with AD (PWD) will nearly triple from 5.2 million in 2014 to a projected 13.8 million in $2050 .^{6}$

These demographic trends simultaneously affect caregiving populations. Currently, there are 65.7 million informal caregivers in the US. ${ }^{7,8}$ Over $90 \%$ of older adults with chronic disabilities receive some care support, and about two-thirds receive only informal unpaid care. ${ }^{2}$ Specifically, 43.5 million family members accept responsibility for providing informal, unpaid care for older adults, and 15.5 million are caring for PWD. ${ }^{6,8}$

Most older adults, including PWD, desire to remain in their homes as they age. ${ }^{9}$ Declining physical and mental capabilities create significant challenges to manage increasing care needed to remain living at home. Since the 1980s, technology has been investigated as a possible support for aging in place. ${ }^{10}$ Technology-based interventions currently employed to support caregivers of PWD range from internetbased information and support groups to robotic companions and use of smartphones to report symptoms. ${ }^{11-13}$ As technology advances, so will new opportunities to reduce both the burden of caregiving and the need for premature nursing home placement due to caregivers no longer being able to meet care demands. This paper focuses on telemedicine and smart technologies as potential supports for the growing population of PWD and their family caregivers.

While this paper is not a systematic review, the authors conducted a similar search. Search terms for technology, telehealth/telemedicine, and sensor, monitoring, and tracking technology were combined with moderating terms like rural health and dementia caregiving to find articles with comprehensive reviews, exemplars of uses, and experimental or unique reports of applications. No criteria were developed for inclusion or exclusion of articles.

\section{Costs and negative outcomes of caregiving}

Cognitive impairment, including memory loss and related neurodegenerative diseases, is placing increasing demands on US health care and family systems. In 2014, the medical cost of caring for PWD is estimated at $\$ 214$ billion; the expected medical cost in 2050 is projected to be $\$ 1.2$ trillion. ${ }^{6}$ The annual overall Medicare and Medicaid expenditure for dementia care is $\$ 150$ billion for acute, long-term, and hospice care. ${ }^{6}$ Uncompensated contributions of family caregivers were estimated at $\$ 202.6$ billion in 2010 considering an hourly wage of $\$ 11.93$ per hour. ${ }^{6,7}$ PWD have more than triple the number of hospitalizations and nursing home admissions compared with older adults with other conditions. AD and other types of dementia are the sixth leading cause of death. ${ }^{6}$

Family caregivers experience high levels of stress, burden, and role captivity that lead to negative physical, psychological, social, and spiritual outcomes. ${ }^{14-16}$ Caregivers of PWD must cope with their loved one's progressive memory loss, self-care impairment, and communication breakdown. Additional caregiver challenges include learning new skills to manage disruptive behaviors; altered manifestations of behavioral and psychological symptoms that are common, progressive, and change in dementia; and complex conditions such as delirium that require guidance from health care professionals. ${ }^{17-19}$ Caregiving stress, strain, and burden contribute to negative physical and mental health outcomes that include depression, insomnia, and psychotropic medication use, with notable increases in caregiver morbidity and mortality. ${ }^{20,21}$

Different types of caregivers face unique challenges. Spousal caregivers may experience grieving due to changes in their relationship with their life partner. They may struggle to physically manage care or suffer cognitive changes themselves. Children and younger spousal caregivers may have occupational stress and career changes and may still be caring for their children while balancing care for parents or a spouse with AD. Caregivers separated by distance face unique challenges as they manage caregiving from afar. They may worry about their family member's safety and security, medication schedules, wandering, and need for information and socialization. The distant caregiver may be totally unaware of the needs of their family member, placing further burden on the onsite caregiver(s). ${ }^{6}$

\section{Telemedicine and e-health}

Telemedicine and e-health services are now widely used and well integrated into the daily lives of middle-aged and older adults. Over $50 \%$ of those aged over 65 years use computers and related devices daily to access the internet to seek medical information and social support. ${ }^{22}$ Surveys of family caregivers report that $80 \%-95 \%$ request mobile systems and find that interactive features assist in caregiving. Two-thirds of family caregivers in the US have a mobile wireless device, and $69 \%$ of these report that it assists them in caregiving. Mobile technology features such as mobile text messaging, personal medical recording, and visual communication with health care providers meet specific user needs. ${ }^{22-24}$

Telemedicine and e-health services are now available to support care for older adults and family caregivers. Virtual care in the community delivered via technology-based 
approaches is able to overcome the limitations of face-to-face delivery; namely, time constraints, geographic limitations, and transportation issues. ${ }^{25}$ For those dealing with earlystage $\mathrm{AD}$, key considerations are 1) identifying the needs of cognitively impaired adults and their family caregivers, 2) developing technological applications suitable for constrained environments and user abilities, 3) establishing training strategies for cognitively impaired adults to use the technologies, and 4) providing appropriate technical support for cognitively impaired adults and caregivers. ${ }^{26}$

\section{PWD use of technology}

Online or internet-based technology can support PWD themselves, especially in early stages. There have been several studies testing online resources for PWD focused on maintaining cognitive skills, learning new things, maintaining social interactions, and finding information. ${ }^{27}$ Examples include electronic applications providing reminders (eg, medication management prompting devices), social contact (eg, cellphones, online chat groups), safety (eg, alarm systems and action triggered lighting), and daily activities (eg, music players). Cognitive stimulation activities are also often web or computer based. Cognitive stimulation has been shown to have positive effects in PWD in early and mid stages. ${ }^{28}$

\section{Caregiver support through technology}

Although technology can target the PWD themselves, the vast majority of telemedicine and smart technologies are designed to support family caregivers. Two separate systematic reviews highlight the benefits of web-based caregiver support programs. ${ }^{29}$ Web-based training and educational programs to support caregivers are readily available. The Internet-Based Savvy Caregiver, based on the validated Savvy Caregiver program, ${ }^{30}$ is an example. It provides an interactive, iterative curriculum that improves knowledge about, and competence for, caregiving. ${ }^{25}$

A customized computer-telephone integration system, e-care, provides a psychoeducational intervention that identifies resources and strategies to enhance safety, communication, self-care, social support, and management of problem behaviors in the community. ${ }^{31}$ The system features screen phones with hierarchal menus (text and voice) that enables users to 1) place and receive calls, 2) send and retrieve messages, 3) access a range of information and services, and 4) conference with several people simultaneously. This system was effective in decreasing caregiver burden and depression significantly in depression scores in caregivers with high depression scores at baseline. ${ }^{31}$
Another type of in-home caregiver support links caregivers with expert guidance for managing challenging care situations using video monitoring. Caregivers are trained to capture behaviors that are a problem via computer video recording, which is then wirelessly uploaded for a team of experts to review and provide feedback. In a pilot study, this system demonstrated improved behavior management and caregiver communication and was reported as easy to use. ${ }^{32}$ Support for caregivers can also be provided via web-based video conferencing and/or text-based chat forums. ${ }^{33}$

There is growing use and acceptance of video conferencing in both the diagnosis and monitoring in geriatric medical ${ }^{34}$ and geriatric psychiatry care. ${ }^{35-37}$ Though further large-scale studies are needed, research has established the reliability and validity for neurocognitive testing and neurological examinations via video telemedicine. ${ }^{35,37,38}$ Video conferencing can also link local primary care professionals to specialists for assessments, enhancing the administration of standardized assessments and examinations. ${ }^{35,36}$ Telehealth diagnosis and monitoring have been welcomed in remote and rural areas and with Spanish-speaking and Native American populations, as access to specialized services is limited in these underserved areas. ${ }^{39,40}$

\section{Monitoring systems}

It is widely recognized that caregiving is burdensome and leads to excessive levels of stress; thus, technology must be adapted to address the causes of caregiver stressors. For example, caregivers are concerned about the safety and security of their PWD. It is stressful if the caregiver needs to leave the PWD at home alone for any length of time or while they work, due to possible wandering, accidents, or other negative events that may harm the PWD. Technology that monitors whether or not the PWD leaves the home, falls, or enacts other behaviors and potentially dangerous environmental conditions (eg, heat, water on the floor, fire) may alleviate some of these concerns. Many new systems provide these types of monitoring and tracking systems. Three main aims of monitoring are detection of activities of daily living (ADLs), occurrence of significant events (ie, falls), and changes in health status, or a combination of these. ${ }^{41}$

Monitoring systems are designed to detect changes in one or more ADLs or physical parameters. Detection of subtle changes can trigger interventions to avert negative outcomes such as hospitalizations. In a systematic review, Peetoom et $\mathrm{al}^{41}$ categorized existing monitoring technologies into five categories: 1) in-home passive infrared motion sensors, 2) body-worn sensors, 3) video monitoring, 
4) pressure sensors, and 5) sound recognition integrated with multicomponent systems and "smart homes". An example of simple monitoring is a motion detector that turns on a bathroom light or a wireless home security system that is triggered by exiting or entering, activating an alarm. This technology gathers information through activity sequence awareness, location awareness, presence awareness, and context awareness capabilities. ${ }^{42}$ Initially, data are captured to identify patterns for the individual over time. Systems are developed to code behavior using computer-derived algorithms to identify patterns that deviate from normal and trigger warnings. ${ }^{43}$ Requisite to this system is a person capable of receiving and responding to the alarm to alleviate or intervene on the alarm upon notification.

Other sensor technologies monitor the progression of $\mathrm{AD}$ over time. Changes in ADLs and instrumental ADL performance provide objective data about disease progression. ${ }^{44}$ Through sensor technology, health care providers are able to detect cognitive decline reflected in behaviors such as getting out of bed at odd hours or going to bed earlier and earlier from day to day. ${ }^{44}$ Yefimova and Woods ${ }^{45}$ also describe use of sensor technologies 1) to identify patterns of baseline norms of activities through multimodal awareness monitoring and then 2) to detect the onset or escalation of disruptive behaviors. Repetitive motions might be "normal" in the bathroom when one is brushing teeth, though might indicate increased agitation if it occurs when sitting down. ${ }^{45}$

A commercially available example is the QuietCare system, which monitors ADLs. ${ }^{43}$ The QuietCare system requires a response to the alarms, activated through emails to caregivers, and in urgent situations to a 24/7 regional emergency center. In a Dutch study on psychogeriatric patients living at home alone, there was a significant decrease in burden for formal or informal caregivers at a distance. ${ }^{43}$

\section{Ambient assistive living with smart technologies}

Ambient assistive living (AAL) integrates telecommunications, electronics, and computing to support people in carrying out their everyday life activities to support continued independent living at home or in an apartment. AAL results from a new comprehensive technologic paradigm called "ambient intelligence". ${ }^{46}$ The technology is focused on empowering human-machine interactions by using sensitive, adaptive, and responsive strategies to human needs in digital environments. ${ }^{46} \mathrm{AAL}$ is characterized by "sensors and devices interconnected through a network ... which senses features of the users and their environment, then reasons about the accumulated data, and finally selects actions to take that will benefit the users in the environment"10 (p. 278). Complex AAL systems can include multiple sensor devices located within an environment, such as Bluetooth Low Energy, radiofrequency identification, microchip implant, sensor technology, software agents (a software program that has some capacities of artificial intelligence), affective computing, and biometrics (some include nanotechnology).

"Smart homes" are one example of complex AAL and use remote network monitoring and exchange of data at a distance. AAL technologies can 1) monitor ambient temperatures, gases, and motion; 2) notify problematic changes to remote users; and 3 ) enable family and health care providers to predict and intervene on impending incidents. ${ }^{47,48}$ For example, a stove temperature sensor can collect real-time temperature data. If the stove has been left on for too long, data points indicating the temperature are detected, compared, and then analyzed in order to generate an alert for distance caregivers. ${ }^{47}$

At Tiger Place, an assisted living facility in Columbia, MI, USA, an aging in place initiative uses this type of complex monitoring system. A wide variety of data are collected using 1) infrared sensors detecting motion on kitchen cabinets while preparing meals and 2) bed pneumatic sensors assessing levels of pulse, respiration, and restlessness. ${ }^{48}$ Algorithms are developed to analyze these data to identify functional decline and potential illnesses. Then, health care providers such as nurse practitioners provide timely and effective care to improve and maintain health and functional independence. ${ }^{48}$ While this system is scientifically verified, it is not used in home settings yet because it requires expensive advanced technologies and intensive training for health care providers.

\section{Wayfinding and tracking}

Wayfinding technologies can assist PWD in living safely by providing prompts for independent mobility within a home and community. ${ }^{49}$ Wayfinding systems typically use global positioning systems (GPS) that allow PWD in earlier stages to increase freedom, autonomy, and confidence in being able to go outdoors independently without fear of becoming lost. Orientation assistance can be given through three modalities, visual, audio, and tactile signals, or a combination, and have been tested indoors and outdoors. ${ }^{50}$ An example of a tactile-based system uses four small vibrating motors attached to a wearable belt with an integrated GPS, a threeaxis compass, an inertial sensor, power management, a battery, and an algorithmic executive processor that provides 
the PWD with direction-relevant cues on which way to go. ${ }^{51}$ The effectiveness of this system is limited to PWD in mild stages, because of cognitive demands for perceiving and interpreting the sensations.

Another navigation system using scenario-based video clips embedded with Bluetooth sensor technology was developed and tested with some success on cognitively intact individuals. ${ }^{49}$ Lancioni et $\mathrm{al}^{52,53}$ have done studies on navigational systems using either light or auditory cues, finding consistently that visual cues are more effective wayfinding cues for PWD.

In contrast, tracking devices use similar technology but focus on providing caregivers with a way to know the location of the PWD and to prevent and intervene in unsafe situations. A pilot study evaluated the feasibility and acceptability of a GPS device with expanded features for 1) tracking location and tracing path through satellite, 2) programming telephone connection between the PWD and the family caregivers, and 3) activating a loudspeaker function to communicate with the PWD in case they cannot use the phone. ${ }^{54}$ This study of dyads $(\mathrm{N}=33)$ found that the GPS intervention increases the ability of PWD to go outside independently, results in more freedom of PWD away from caregivers, and decreases levels of stress of both PWD and caregivers. ${ }^{54}$

Another example using complex tracking programs is prevention of nighttime falls in PWD. This tracking program, HBTec-TS system, incorporates a nightlight path device that is installed near the bed and is triggered to light up automatically when the person steps out of bed. The lighting guides the PWD to the bathroom at night. In addition, this system can be integrated with a wrist band similar to LifeLine $^{\circledR}$, a remote intercom, and a connection to a hotline for emergency personnel. ${ }^{55}$ A recent study using the HBTec-TS system reported a significant decrease in nighttime falls in the intervention group $(\mathrm{N}=49)$ compared with the control group $(\mathrm{N}=47)$ of community-dwelling PWD (odds ratio $=0.37$, $95 \%$ confidence interval $=0.15-0.88, P=0.02)$. This system reduced the relative risk of falls by $48.8 \%$ in PWD at high risk for frequent falls. ${ }^{55}$

\section{Perspectives of users}

Several qualitative studies ${ }^{54,57,58}$ describe the responses of caregivers and PWD to technology. Caregiver views did vary and they expressed both positive feelings and concerns. For example, caregivers felt that GPS technology has the opportunity to promote autonomy, mobility, and safety of the PWD while providing family member caregivers with peace of mind. However, these tracking devices are not helpful for every PWD and may lead to diminished privacy and dependency. ${ }^{56}$ In general, technology that allows people to remain more independent and reside at home safely is rated positively. ${ }^{54,57,58}$ Span et $\mathrm{al}^{59}$ found that involving the PWD in the process of developing technological applications enhanced usability and acceptability and contributed to a sense of empowerment.

Specific to sensor networks, Steel et $\mathrm{al}^{57}$ identified six major themes related to the use of technology that potentially affect users' acceptance. These include valuing independence and related perceptions of nursing homes, the perceived impact on quality of life and potential changes in lifestyle, and concerns about cost, social implications, adherence, health, confidentiality, anxiety, and system reliability. In addition, user preferences related to technology self-efficacy and willingness to be trained, design preferences such as type of technology (wearable, ambient monitoring, or embedded sensors), and external factors involving support availability were related issues. ${ }^{57}$ In another study, older users saw technology as a support to aging in place, citing increased feelings of safety and security, thus postponing institutionalization. ${ }^{58}$ Studies indicated that systems should be not only unobtrusive and acceptably installed but easy to use.

\section{Challenges to adoption}

There are various barriers that limit the use of technology by PWD and their caregivers, including 1) ethical considerations; 2) user perspectives; 3 ) access to, and reimbursement for, technology; and 4) privacy. Privacy is a major concern, specifically when technological devices utilize recorded video and audio of PWD and caregivers with a risk of exposing sensitive, personally identifiable data. The Health Insurance Portability and Accountability Act of 1996 must be adhered to regarding all data that are obtained through the technological devices in the home. ${ }^{46}$ Obtaining informed consent of the PWD and their caregivers is extremely important before the implementation of technology devices in the home. All collected data should be encrypted and secure, in order to maintain and ensure confidentiality.

The use of technology in the home has the potential to reduce autonomy of PWD. Technology can become too controlling and violate privacy. Restrictions and automations are intended to support independent living; however, unnecessary and too frequent use of technologies easily diminishes independence of choice and action of the PWD living in their home. Instead of being helpful, extremely advanced technology beyond the user's capacity can become frustrating and dehumanizing to the PWD. ${ }^{58,60}$ Significant time must be 
spent on educating and ensuring understanding of each type of technological device that will be used in the home. ${ }^{58}$

There may also be stigma associated with the technology. Families may be apprehensive about the presence of technology in the home, with the belief that such devices are used only for dependent and frail older adults. ${ }^{60}$ There are concerns that technology that is obtrusive and visible may cause potential embarrassment and anxiety. Devices should be designed to minimize attracting attention; for example, using a smartphone for a technological application is discreet and can help avoid stigmatization. ${ }^{46}$ In addition, alarms should not be too loud. Features should be designed to alert the caregiver but prevent agitation and avoid frightening the PWD. ${ }^{61}$

A critical factor in acceptance of technology is ease of use. $^{62}$ This is especially pertinent for PWD whose caregivers are themselves aging and may have limited experience and different attitudes toward technology. Spousal caregivers may also be of advanced age with corresponding physical and cognitive changes such as reduced processing speed, less manual dexterity, and low visual acuity. There is a risk that older adults may feel frustrated if they frequently fail in using devices, and they may find technology use as another burdensome caregiving task.

There is also concern that technology use may result in loss of human contact. Technology devices enable PWD to increase their independence. Thus, PWD may need less frequent contact with formal or informal caregivers. This increased independence could result in social isolation and loneliness of the PWD. ${ }^{60}$ It is important to guarantee that the technology devices in the home do not replace human care and contact. ${ }^{46}$

Socioeconomic barriers exist. For example, internet access is a necessary requirement of many advanced technologies. However, families of PWD living in rural areas or with low incomes may have limited internet access. Dial-up services used in some areas by some older adults may not meet capacity for data transfer. Indeed, the number of persons aged 65 years and older with high-speed internet connections has increased to $39 \%$ from $19 \%$ in 2008 , but it still has far to go to achieve universal access. ${ }^{63}$ Modest incomes of older adults may be to blame in part, and older adults may not see the value of high-speed internet access.

Insurance coverage for new technology to support dementia care is also lagging. Consumers must be able to afford these services, as many emerging technologies are not covered by personal health insurance, Medicare, or Medicaid. Who will handle the finances associated with installing and utilizing the technology is a major concern of PWD and their caregivers. ${ }^{60}$ If technology requires an out-of-pocket expense, they are less likely to use technology, even though they know that it could be beneficial for care.

\section{Future directions}

Technological devices must be designed with end user ease in mind in order to be functional and accepted. It is important to select the most appropriate devices based on the user's need and their technological competence. For example, devices must be power efficient to avoid unexpected powering off. ${ }^{61}$ Devices should require minimal configuration such as repeated need to log on and enter passwords. ${ }^{46}$ User manuals should be available for reference featuring a large font and diagrams of limited complexity.

Sufficient training for PWD and their family caregivers is critical when technological devices are introduced and implemented in the home. These technologies must be simple and limited in focus and should not require fine motor skills or excessive cognitive processing. Consideration of adults' learning styles is also essential in training older adults to use advancing technologies. A hands-on approach (experiential learning style) is essential to developing competency in technology use by older adults. PWD and their caregivers should be involved in developing and testing these technologies. ${ }^{64}$ Ongoing tech support and resources for troubleshooting that are readily accessible will also be needed.

Health care providers must also be prepared to screen, analyze, and interpret data and respond ${ }^{60}$ and may need technical support and training. Providing care through e-health and other technologies may require the acquisition and practice of new skills for health care professionals. For example, clinicians using technology in working with older adults need to be aware of potential isolation effects. Research is needed to determine appropriate levels of in-person contact that technology can supplement. Special skills and strategies for providing care with technology need to be identified through research and incorporated into educational programs for health professionals.

Proactive policy support is needed to make consumers aware of available technologies to support care for PWD. The leading factor driving acceptance and use of technology is perceived value (usefulness) or meeting a need. ${ }^{62}$ Marketing available technologies to make consumers aware of these supports will play a crucial role. ${ }^{64}$ In addition, access to internet infrastructure is critical to use of technology to support dementia care in the home. The Federal Communication Commission developed a National Broadband Plan in 2010 
and identified how high-speed internet access is essential for older adults for next-generation internet technologies that include telehealth and smart homes, supporting needs of older adults, including personal fulfillment, health preservation, social connectedness, caregiver support, and functional capability and activity. ${ }^{63}$

Ethical principles should be applied to protect PWD users from potential negative aspects of technology. Mahoney et $\mathrm{al}^{65}$ developed a list of ethical principles for gerotechnology research and development targeting persons with $\mathrm{AD}$ and their caregivers. Their guidelines state how to maintain respect, autonomy, beneficence, justice and distributional fairness, nonabandonment, and privacy and confidentiality. ${ }^{65}$ Stringent regulation should be applied for data collection, deidentification, data storage, distribution of study findings, as well as secondary data use. All data collected by technology should have a clear purpose that will benefit the user.

Future research is needed to demonstrate costeffectiveness to support changes in reimbursement policies. Expansion of telehealth under the Affordable Care Act is projected to increase telehealth services $500 \%$ by $2017 .{ }^{66}$ Support by official agencies such as the Administration on Aging or endorsement by the Alzheimer's Association may also increase consumer use.

Even though the US is considered an early adopter of technology, it actually lags behind other countries in adoption of health care technologies by up to 12 years. ${ }^{67,68}$ The US lacks an integrated network of connectivity, a key that has enabled smaller countries to implement technology-driven health solutions. ${ }^{68}$ A review of selected technology innovations completed by $\mathrm{Chan}_{\mathrm{et}} \mathrm{al}^{69}$ found that many systems were designed in Europe. In Japan, the Ministry of International Trade and Industry built 13 "welfare techno houses" that were equipped with fully automated biomedical devices. ${ }^{70}$ The Japanese also developed electrical appliances fitted with sensors (eg, rice cooker, air conditioning, refrigerator, TV set) to monitor activities such as having or preparing a meal or bathing. Raw data are translated using mathematical models into usable behavioral data. ${ }^{71}$

\section{Cutting-edge technologies}

Wearable, implantable (microcapsule devices that are swallowed), and microsystems are being developed and are available on a limited basis. Devices that are worn by the user or embedded in the home are connected by wired or wireless networks to a service center that has monitoring and diagnostic capabilities. These devices capture data from sounds, images, body motion, and ambient parameters (light, temperature, humidity), vital signs (blood pressure, respiration, body temperature, heart/pulse rate, bodyweight/ fat, blood oxygenation, electrocardiogram), sleep patterns and other health parameters, daily activities, and social interactions. Algorithms compare data with an established profile of the user's physical and physiological patterns and can provide alerts and assistance for emergency situations. Wearable (machine washable) garments with sensors are being designed in the US and other countries. These units measure a variety of physiologic parameters and can also be embedded with tracking technology. ${ }^{72}$

Robot technology has been more fully developed to assist in supporting basic activities (getting dressed, bathing, toileting, eating) and mobility, providing household maintenance, monitoring those who need continuous care, and maintaining safety. Robots have been designed with consideration of social, aesthetic, and emotional factors to support the quality of life of older adults. ${ }^{10}$

\section{Conclusion}

As the population with dementia expands and increases the burden on family caregivers, telemedicine and smart technologies have potential to support aging in place for PWD while reducing caregiver burden and its negative outcomes, improving quality of life for families experiencing dementia and reducing health care costs. Finally, the potential for technology to support dementia care at home may reduce health care expenditures secondary to formal care needs and premature institutional care. However, realizing the potential for technology to meet dementia care needs depends on a number of factors, including raising awareness of available technologies and their utility, promoting accessibility and affordability, and overcoming challenges to acceptance and use. Future research and continuous development are required to use advanced technology integrated with current dementia care.

\section{Disclosure}

The authors report no conflicts of interest in this work.

\section{References}

1. Vincent G, Velkoff V. The Next Four Decades: The Older Population in the United States: 2010 to 2050. Washington: US Census Bureau, US Government Printing Office; 2010

2. US Department of Health and Human Services. A Profile of Older Americans: 2011. Available from: http://www.aoa.gov/Aging Statistics/Profile/2011/docs/2011 profile.pdf. Accessed January 7, 2015.

3. Lopez OL, Jaqust JW, DeKosky ST, et al. Prevalence and classification of mild cognitive impairment in the Cardiovascular Health Study Cognition Study. Arch Neurol. 2003;60(10):1385-1389. 
4. Farias ST, Mungas D, Reed BR, Harvey D, DeCarli C. Progression of mild cognitive impairment to dementia in clinic-vs community-based cohorts. Arch Neurol. 2009;66:1151-1157.

5. Hebert LE, Beckett LA, Scherr PA, Evans DA. Annual incidence of Alzheimer disease in the United States projected to the years 2000 through 2050. Alzheimer Dis Assoc Disord. 2001;15(4):169-173.

6. Alzheimer's Association. 2014 Alzheimer's Disease Facts and Figures. Available from: http://www.alz.org/downloads/facts_figures_2014.pdf. Accessed January 7, 2015.

7. Family Caregive Alliance. Selected Caregiver Statistics. 2012. Available from: https://caregiver.org/selected-caregiver-statistics. Accessed January 7, 2015.

8. National Alliance for Caregiving in collaboration with AARP. Caregiving in the US Executive Summary. 2009. Available from: http:// www.caregiving.org/pdf/research/CaregivingUSAllAgesExecSum.pdf. Accessed January 7, 2015.

9. Centers for Disesase Control and Prevention. The State of Aging and Health in America 2013. Available from: http://www.cdc.gov/aging/ help/dph-aging/state-aging-health.html. Accessed January 7, 2015.

10. Cook DJ, Augusto JC, Jakkula VR. Ambient intelligence: technologies, applications, and opportunities. Pervasive Mob Comput. 2009;5(4):277-298.

11. Czaja SJ, Rubert MP. Telecommunications technology as an aid to family caregivers of persons with dementia. Psychosom Med. 2002;64: 469-476.

12. Powell J, Chiu T, Eysenbach G. A systematic review of networked technologies supporting carers of people with dementia. $J$ Telemed Telecare. 2008;14(3):154-156.

13. Steis M, Prabhu V, Kolanowski A, et al. Detection of delirium in community-dwelling persons with dementia. Online J Nurs Inform. 2012;16(1).

14. Brodaty H, Green A. Who cares for the carer? The often forgotten patient. Aust Fam Physician. 2002;31(9):833.

15. Schulz RS, Sherwood PR. Physical and mental health effects of family caregiving. Am J Nurs. 2008;108(Suppl 9):23-27.

16. Zarit, S. Assessment of Family Caregivers: A research perspective. San Francisco; CA. Family Caregiver Alliance. 2006.

17. Fick DM, Kolanowski AM, Waller JL, Inouye SK. Delirium superimposed on dementia in a community-dwelling managed care population: a 3-year retrospective study of occurrence, costs, and utilization. J Gerontol A Biol Sci Med Sci. 2005;60(6):748-753.

18. Moniz-Cook E, Elston C, Gardiner E, et al. Can training community mental health nurses to support family carers reduce behavioural problems in dementia? An exploratory pragmatic randomised controlled trial. Int J Geriatr Psychiatry. 2008;23(2):185-191.

19. Woods B, Clare L. Psychological interventions with people with dementia. Handbook of the Clinical Psychology of Ageing. Chicester, UK: John Wiley and Sons, Ltd; 2008:523-548.

20. Monin J, Schulz R. Interpersonal effects of suffering in older adult caregiver relationships. Psychol Aging. 2009;24(3):681-695.

21. Montgomery RJ, Kosloski KD. Pathways to a caregiver identity and implications for support services. Caregiving Across the Lifespan. New York: Springer; 2013:131-156.

22. Fox S, Brenner J. Family Caregivers Online. Washington, DC, USA. 2012. Available from: http://www.pewinternet.org/2012/07/12/familycaregivers-online/. Accessed 25 October, 2014

23. UnitedHealthcare. National Alliance for Caregiving. e-Connected Family Caregivers: Bringing Caregiving into the 21st Century. 2012; http://www.caregiving.org/data/FINAL_eConnected_Family_Caregiver_Study_Jan\%202011.pdf. Accessed January 25, 2015. Accessed November 14, 2014.

24. Mollenkopf H, Fozard JL. Technology and the good life: challenges for current and future generations of aging people. Annu Rev Gerontol Geriatr. 2003;23:250-279.

25. Lewis ML, Hobday JV, Hepburn KW. Internet-based program for dementia caregivers. Am J Alzheimers Dis Other Demen. 2010;25(8): 674-679.
26. Armstrong N, Nugent C, Moore G, Finlay D. Using smartphones to address the needs of persons with Alzheimer's disease. Annals of Telecommunications. 2010;65(9-10):485-495.

27. Rosenberg L, Nygard L. Persons with dementia become users of assistive technology: a study of the process. Dementia. 2011;11(2):135-154.

28. Woods B, Aguirre E, Spector AE, Orrell M. Cognitive stimulation to improve cognitive functioning in people with dementia. Cochrane Database Syst Rev. 2012;15;2:CD005562.

29. Godwin KM, Mills WL, Anderson JA, Kunik ME. Technology-driven interventions for caregivers of persons with dementia a systematic review. Am J Alzheimers Dis Other Demen. 2013;28(3):216-222.

30. Hepburn KW, Lewis M, Sherman CW, Tornatore J. The Savvy Caregiver program: developing and testing a transportable dementia family caregiver training program. Gerontologist. 2003;43(6):908-915.

31. Finkel S, Czaja SJ, Martinovich Z, Harris C, Pezzuto D, Schulz R. E-care: a telecommunications technology intervention for family caregivers of dementia patients. Am J Geriatr Psychiatry. 2007;15(5):443-448.

32. Williams K, Arthur A, Niedens M, Moushey L, Hutfles L. In-home monitoring support for dementia caregivers: a feasibility study. Clin Nurs Res. 2013;22(2):139-150.

33. Marziali E, Garcia LJ. Dementia caregivers' responses to 2 internetbased intervention programs. Am J Alzheimers Dis Other Demen. 2011;26(1):36-43.

34. van den Berg N, Schumann M, Kraft K, Hoffmann W. Telemedicine and telecare for older patients: systematic review. Maturitas. 2012;73(2): 94-114.

35. Barton C, Morris R, Rothlind J, Yaffe K. Video-telemedicine in a memory disorders clinic: evaluation and management of rural elders with cognitive impairment. Telemed J E Health. 2011;17(10):789-793.

36. Martin-Khan M, Flicker L, Wootton R, et al. The diagnostic accuracy of telegeriatrics for the diagnosis of dementia via video conferencing. J Am Med Dir Assoc. 2012;13(5):487. e419-487. e424.

37. Munro Cullum C, Hynan L, Grosch M, Parikh M, Weiner M. Teleneuropsychology: evidence for video teleconference-based neuropsychological assessment. J Int Neuropsychol Soc. 2014;20(10):1-6.

38. Morgan D, Innes A, Kosteniuk J. Dementia care in rural and remote settings: a systematic review of formal or paid care. Maturitas. 2011; 68(1):17-33.

39. Vahia IV, Ng B, Camacho A, et al. Telepsychiatry for neurocognitive testing in older rural Latino adults. Am J Geriatr Psychiatry. In press 2014.

40. Weiner MF, Rossetti HC, Harrah K. Videoconference diagnosis and management of Choctaw Indian dementia patients. Alzheimers Dement. 2011;7(6):562-566.

41. Peetoom KK, Lexis MA, Joore M, Dirksen CD, De Witte LP. Literature review on monitoring technologies and their outcomes in independently living elderly people. Disabil Rehabil Assist Technol. Epub September 24, 2014.

42. Mulvenna MD, Carswell W, McCullagh PJ, et al. A review of the role of assistive technology for people with dementia in the hours of darkness. Technol Health Care. 2009;17(4):281-304.

43. Lexis M, Everink I, van der Heide L, Spreeuwenberg M, Willems C, de Witte L. Activity monitoring technology to support homecare delivery to frail and psychogeriatric elderly persons living at home alone. Technol Disabil. 2013;25:189-197.

44. Doctor F, Iqbal R, Naguib R. A fuzzy ambient intelligent agents approach for monitoring disease progression of dementia patients. J Ambient Intell Human Comput. 2014;5:147-158.

45. Yefimova M, Woods D. Using sensor technology to monitor disruptive behavior of persons with dementia. AAAI Technical Report FS-12-01 Artificial Intelligence for Gerontechnology. 2012:51-54.

46. Rashidi P, Mihailidis A. A survey on ambient assisted-living tools for older adults. IEEE J Biomed Health Inform. 2013;17(3):579-590.

47. McKenzie B, Bowen ME, Keys K, Bulat T. Safe home program: a suite of technologies to support extended home care of persons with dementia. Am J Alzheimers Dis Other Demen. 2013;28(4):348-354. 
48. Rantz MJ, Skubic M, Miller SJ, et al. Sensor technology to support aging in place. J Am Med Dir Assoc. 2013;14(6):386-391.

49. Chang Y-J, Wang T-Y. Comparing picture and video prompting in autonomous indoor wayfinding for individuals with cognitive impairments. Pers Ubiquitous Comput. 2010;14(8):737-747.

50. Korhonen M. Mobile augmented teleguidance-based safety navigation concept for senior citizens. AMK-lehti/Journal of Finnish Universities of Applied Sciences. 2012(2).

51. Grierson LE, Zelek J, Lam I, Black SE, Carnahan H. Application of a tactile way-finding device to facilitate navigation in persons with dementia. Assist Technol. 2011;23(2):108-115.

52. Lancioni GE, Perilli V, Singh NN, et al. Persons with mild or moderate Alzheimer's disease use a basic orientation technology to travel to different rooms within a day center. Res Dev Disabil. 2011;32(5): 1895-1901.

53. Lancioni GE, Singh NN, O'Reilly MF, Sigafoos J, Oliva D. Assistive technology for people with severe/profound intellectual and multiple disabilities. Assistive Technologies for People with Diverse Abilities. New York: Springer; 2014:277-313.

54. Pot AM, Willemse BM, Horjus S. A pilot study on the use of tracking technology: feasibility, acceptability, and benefits for people in early stages of dementia and their informal caregivers. Aging Ment Health. 2012;16(1):127-134.

55. Tchalla AE, Lachal F, Cardinaud N, et al. Preventing and managing indoor falls with home-based technologies in mild and moderate Alzheimer's disease patients: pilot study in a community dwelling. Dement Geriatr Cogn Disord. 2013;36(3-4):251-261.

56. Landau R, Auslander GK, Werner S, Shoval N, Heinik J. Who should make the decision on the use of GPS for people with dementia? Aging Ment Health. 2011;15(1):78-84.

57. Steele R, Lo A, Secombe C, Wong YK. Elderly persons' perception and acceptance of using wireless sensor networks to assist healthcare. Int J Med Inform. 2009;78(12):788-801.

58. van Hoof J, Kort HS, Rutten PG, Duijnstee MS. Ageing-in-place with the use of ambient intelligence technology: perspectives of older users. Int J Med Inform. 2011;80(5):310-331.

59. Span M, Hettinga M, Vernooij-Dassen M, Eefsting J, Smits C. Involving people with dementia in the development of supportive IT applications: a systematic review. Ageing Res Rev. 2013;12(2):535-551.
60. Zwijsen SA, Niemeijer AR, Hertogh CM. Ethics of using assistive technology in the care for community-dwelling elderly people: an overview of the literature. Aging Ment Health. 2011;15(4):419-427.

61. Applegarth SP, Rowe M, Kearns W, Bowen ME. Activation thresholds and operating characteristics of commercial alarm products to provide surveillance for dementia caregivers. Gerontechnology. 2013;11(3):480-487.

62. Kramer B. Dementia caregivers in Germany and their acceptance of new technologies for care: the information gap. Public Policy and Aging Report. 2013;24(1):32-34.

63. Baker C, Seegert L. A Platform for Aging in Place: The Increasing Potential of High-speed Internet Connectivity. Available from: http:// www.aarp.org/content/dam/aarp/research/public_policy_institute/ cons_prot/2013/potential-of-high-speed-internet-connectivity-AARPppi-cons-prot.pdf. Accessed January 7, 2015.

64. Lee C. Adoption of smart technology among older adults: challenges and issues. Public Policy and Aging Report. 2013;24(1):14-17.

65. Mahoney DF, Purtilo RB, Webbe FM, et al. In-home monitoring of persons with dementia: ethical guidelines for technology research and development. Alzheimers Dement. 2007;3(3):217-226.

66. Eddy DM, Shah R. A simulation shows limited savings from meeting quality targets under the Medicare shared savings program. Health Affairs. 2012;31(11):2554-2562.

67. Jha AK, Doolan D, Grandt D, Scott T, Bates DW. The use of health information technology in seven nations. Int $J$ Med Inform. 2008;77(12):848-854.

68. Anderson GF, Frogner BK, Johns RA, Reinhardt UE. Health care spending and use of information technology in OECD countries. Health Aff. 2006;25(3):819-831.

69. Chan M, Campo E, Estève D, Fourniols J-Y. Smart homes: current features and future perspectives. Maturitas. 2009;64(2):90-97.

70. Tamura T, Ogawa, Yoda. Fully automated health monitoring system in the home. Med Eng Phys. 1998;20(8):573-579.

71. Matsuoka K. Aware home understanding life activities. Paper presented at: Proceedings of 2nd International Conference On Smart Homes and Health Telematic, ICOST 2004.

72. Patel S, Park H, Bonato P, Chan L, Rodgers M. A review of wearable sensors and systems with application in rehabilitation. $J$ Neuroeng Rehabil. 2012;9:21.
Smart Homecare Technology and TeleHealth

\section{Publish your work in this journal}

Smart Homecare Technology and TeleHealth is an international, peer-reviewed, open access online journal publishing original research, reviews, editorials and commentaries on the application of technology to support people and patients at home and in assisted living centers to optimize healthcare and management resources. Specific topics in the journal include: Development and application of

\section{Dovepress}

devices within the home and embedded in appliances; Healthcare provider communication and education tools; and drug ordering and adherence. The manuscript management system is completely online and includes a very quick and fair peer-review system, which is all easy to use. Visit http://www.dovepress.com/ testimonials.php to read real quotes from published authors. 